\title{
Learning through work: Exploring instances of relational interdependencies
}

\author{
Stephen Billett
}

Griffith University, Australia

\begin{abstract}
This paper provides an account of the inter-psychological processes that constitute learning through work. It does this by drawing on deliberations about the relative contributions of the immediate social world (i.e., workplace setting) that individuals encounter and the personal premises for individuals' learning. This account is realised through analyses of workers' experiences of working and learning in both large and small enterprises. Together, these premises and their contributions are used to elaborate how learning through work proceeds as a process of relational interdependence between the affordance of the workplace and the engagement of workers. This relational process is evident in work of different kinds, from the labours of coalminers through to the entrepreneurial activities of small business operators. Instances of learning through work are elaborated through studies that identify how workplaces' affordances - those that invite workers in particular ways to participate, access support and reward-are generated and projected. These contributions to engaging in and learning through work can be conceptualised as the immediate social contribution or experience that is shaped by cultural and situational factors and the social legacies that shape how individuals construe, engage in, and learn through those practices. It concludes by discussing issues related to both the inter-psychological process and outcomes (e.g., inter-subjectivity) arising from learning through work.
\end{abstract}

\section{Learning through work}

An account of the inter-psychological processes - those between the individuals and the social world - that constitute the process of learning through work is advanced here. This account draws upon a discussion of conceptual premises that inform and illuminate this process of learning, as well as studies of workers' experiences in large and small enterprises. Its purpose is to propose how learning through work can be understood as a process of relational interdependence between the affordance of the workplace, on the one hand, and the engagement of workers, on the other 
(Billett, 2006a). This relational process is evident in work of different kinds, from the labours of coalminers to the entrepreneurial activities of small business operators, and also their learning. In different ways, studies of learning through working life identify how workplaces' affordancesthose that invite workers in particular ways to participate, access support and reward-are generated and projected. These contributions to engaging in and learning through work can be conceptualised as the immediate social contribution or experience that individuals encounter, construe and construct through participating in work activities and interactions. Yet, personal agency, subjectivity, and intentionality also shape individuals' cognitive experience in ways that mediate how they construe, interpret, and construct what is afforded them in workplace settings. Hence, beyond the social contributions to learning it is important to consider those arising from the personal, and, importantly, the relations between the two.

This inter-psychological process of learning through work is necessarily individually negotiated because personal histories or ontogenetic development (i.e., learning across life) are personally unique, in some ways. It seems that personal subjectivities, individuals' gaze (i.e., how they view the world) and the discourses to which they have access, are constituted as part of individuals’ cognitive experience and act to mediate their engagement and learning (Billett, 2006b). Moreover, given the limits and ambiguities in how the social world projects its suggestion (i.e., its contributions, norms and practices), individuals have to actively construe and construct the meaning being suggested by the social world (e.g., the requirements to practise effectively) in learning to respond to new challenges. In this way, workplaces are reliant upon individuals’ agency to secure their continuity through active processes of remaking, learning and transforming the workplace practices as the needs they serve changes However, individual engagement, learning and remaking of practice is also shaped by individuals' dispositions, and brute facts of energy, strength and their limits, as in exhaustion. Consequently, both learning and remaking practice are products of the inter-psychological processes between social and personal contributions: the social suggestion-premised on cultural, social and situational factors, and individuals' intentionality and agency-premised on their history of life experiences, their cognitive experience and how it is deployed. Moreover, the relationship between the two contributions is negotiated and relational, rather than being equal or reciprocal. In one situation and for one individual the press and contribution of the immediate social world might be stronger or weaker. For instance, there may be parts of work in which some workers are more able to 
exercise their personal preferences and interests and ignore the monitoring of supervisors. This consideration of relations between workplace affordances and individual agency contributes to ongoing deliberations in the social sciences about relations between agency and structure. Here, it is proposed that both individuals' learning and societal change arise from complex contributions and negotiation between the social and the personal, not from just one or the other.

The propositions developed here arise through elaborating an account of the relational interdependence between the social and the personal, as an inter-psychological process. Then, the scope, potency, and relational properties of the social contributions to learning and working are discussed. Following this, the role and extent of individuals' relations with the social world are proposed as reasons for restoring and re-emphasising individuals' role in conceptions of learning. The interdependence between social suggestion and individual agency is then elaborated, as is its relational character, through accounts of the inter-psychological processes enacted through engaging in work. In the concluding section, a consideration of the self is advanced to assist conceptualising learning throughout working life or professional development, in terms of intersubjectivity, pedagogy, curriculum and personal epistemologies.

\section{Learning through and for work as relational interdependence}

Learning through work and in workplace settings can be understood in terms of participation in work activities and conceptualised as a negotiated (i.e., relational) interdependence between social and personal factors. That is, learning is the process in and through which workers interact with the social experience they encounter in their workplace, as an inter-psychological process. Yet, as noted, the interactions that comprise this process are mediated by a history of earlier personal (i.e., pre-mediate) socially-derived experiences that shape how individuals interpret and construct what they experience in immediate encounters, such as those in work situations. In this way, the personal constitutes a social legacy, albeit in some ways a potentially unique one. These pre-mediate social experiences both shape and are shaped by individuals' engagement with the immediate social experience, which continues throughout their life histories in particular ways. So, it is this socio-historic person that negotiates the immediate social experiences in workplace settings, which are themselves shaped by history, culture and situation. This is because the immediate social experience of work comprising norms, practices, and techniques is founded on a heritage of concepts and practices that are derived from their historic cultural enactment by 
potentially generations of vocational practitioners and practice, and how these practices and techniques are enacted in particular work situations. The ways and means for conducting work carry cultural precedence that are supported, modified and abandoned as new and different practices and technologies emerge. Yet it is the socio-historic person that shapes what current work practices have become and negotiates the immediate social experience of work. Therefore, and importantly, beyond the changes comprising workers' learning through this negotiation (i.e., between personal and situated factors) this constructive process also constitutes the active remaking and transformation of the culturally-derived practices that comprise paid work.

Given this active and constructive process, the focus and direction of individuals' agency (i.e., their intentional actions) play key roles in the processes of learning and remaking cultural practices. The bases of this intentionality are likely to be located in individuals' subjectivities and capacities that arise from their socially-derived life histories or ontogeneses (Billett \& Somerville, 2004), which shape their cognitive experience. However, its exercise occurs interdependently between the social and the personal. That is, workers need to engage in the socio-culturally-derived and situated practices that comprise the workplace in order to secure the knowledge required for work. While this necessity drives workers' learning and participation, the social practices that constitute the workplace require workers to secure the purposes and goals of the workplace. In this way, workers' needs and practices of ongoing learning are interdependent with the workplace's goals and practices.

Consequently, these two sets of contributions to individual change (e.g., workers' learning) and cultural (e.g., workplace) development are relational. On the one hand, individuals' potentially unique interpretations and enactments of the social suggestion indicate that social agency cannot be uniformly enacted. For instance, an individual might be unaware of the suggestion being made or of the importance of that suggestion. This could arise because it is not apparent or that they lack the concepts to understand. Also, participants will be more or less subject to the social suggestion that is being exercised. The need to adhere to a particular set of practices might be very compelling for an apprentice learning in a workplace, but less so for a valued senior worker. In this way, the capacity of the social world to secure its suggestion is neither comprehensive nor complete when and because this suggestion is limited by the individuals' interpretation (Valsiner, 2000) and standing. On the other hand, personal agency is shaped by the possibilities of engaging in and enacting their work. In this way, individuals' 
freedom and capacity to secure their intentions is in part constrained by the activities their work affords them. In addition, there is the person-dependence of what is experienced. The cultural psychologist Valsiner (2000) refers to the personal novelty of the experiencing of each new event and the need to rebuff much of the social suggestion, which would otherwise overwhelm us (Valsiner \& van de Veer, 2000). In these ways, these negotiations between workers' pre-mediate experiences and immediate experiences of the workplace constitute an ongoing duality between personal and social agency conceptualised as a relational interdependence (Billett, 2006a).

Of particular interest here, the relational character of individuals' capacities to influence the interdependence that constitutes this duality warrants further and deeper consideration. This is because it is only through their participation in and learning through work that the cultural transformations that comprise each change to work practices can be enacted. This concern frames, and is addressed within, this paper. All this prompts the need to go beyond accounts of learning that privilege situational contributions. Instead, a more comprehensive and convincing account of learning throughout working life is needed that includes and reaffirms both the contributions and mediating role of individuals. These contributions are often absent or underrepresented in contemporary conceptions such as activity systems (Engestrom, 1993), communities of practice (Wenger, 1998) and distributed cognition (Salomon, 1997), which tend to privilege the immediate social suggestion. Acknowledging the utility of the socio-historical genesis of knowledge (e.g., Cole, 1998), its particular manifestation in instances of work practice and the situated character of competence are all important and necessary to understand how the social contributions to learning through work are enacted. However, the contemporary emphasis on the situated social experience is insufficient to understand both human and societal development. This is partly because it both mis-represents and under-represents how society's contribution to learning and human development is enacted. The socio-genesis of knowledge is also realised through a person's unique socially-shaped life history or ontogeny. Indeed, the intrapsychological legacy of ontogenetic development is a personal cognitive experience that mediates the construal and construction (i.e., learning) from what is encountered through work and throughout working life, and which, in turn, is developed through that ongoing mediation.

Further, accounts privileging the situational contributions to learning may also ignore how brute facts (Searle, 1995) (e.g., desire, age, disability, perceptual ability) make up part of their cognitive experience and shape workers' engagement with what is experienced. Through 
including individual contributions and mediation, the intent is to reinsert the "subject" that is often missing or de-emphasised in contemporary accounts of learning, such as those offered by activity systems (Engestrom, 1993) and communities of practice (Wenger, 1998). Moreover, in proposing the agency and personal uniqueness of the individual worker, a fundamental question for the social sciences is engaged-what brings about change: society or individuals? Here, personal and social changes are held to be realised through negotiations between both individual and social agency. In all, considerations of self and personal agency are brought centre stage here to propose a more comprehensive account of the socio-geneses of knowledge, learning, and the remaking of work through acknowledging the dual and relational character of this process of knowledge formation.

\section{The socio-geneses of work knowledge as a relational process}

Within theoretical accounts emphasising social contributions to knowledge generation, formation and learning, there is considerable discussion of the relationship between the social and individual. Some hold that the individual is inevitably posterior to the social and is, at best, a placeholder for the social (e.g., Ratner, 2000). Others suggest that the relationship between the individual and social is more balanced (Bhaskar, 1998; Giddens, 1984) or that the social suggestion is something that humans cannot deny (Archer, 2000) or wish away (Searle, 1995). Yet, even given its potential to shape human thinking and acting, the social suggestion is not always comprehensive or wholly compelling in pressing its gift (Giddens, 1991). Lave (1990) describes these practice-based, identity-forming experiences in her study of apprentice tailors living and working in their masters' houses and workshops, in a street full of such workshops. These experiences were apparently an effective way of reproducing the practice of tailoring through processes of observation and imitation. However, as Lave and Wenger (1991) note, other kinds of workplaces may present less potent means for learning practice, because of the weaker potential for exercising such reproduction efforts. Moreover, individuals’ capacity to interpret in a partial or particular way or even rebuff the social suggestion (Valsiner \& van de Veer, 2000) is recognition of the limits of its exercise. For instance, as elaborated later in the paper, despite being subject to the close scrutiny of managers and owners, hairdressers were able to exercise personally-preferred options when engaged in hairdressing (Billett, 2003). In this instance, there is exercised an interplay between strong forms of social press and the individuals' mastery (e.g., 
accountants’ apparent compliance (Grey, 1994)) or appropriation (e.g., hairdressers' exercise of preference) in the process of conducting and learning work. Mastery refers to individuals' superficial and uncommitted compliance to the social practice, for instance in aspects of performance which are public (Wertsch, 1998). Appropriation refers to individuals taking up and becoming committed to what they encounter socially (Luria, 1976).

Humans’ unique capacities for reflective self-evaluation (Taylor, 1985) and exercise of reflexivity (McLaren, 1997) likely free us from some forms of social subjugation. Indeed, even when subjugated, our beliefs and conceptions are not able to be influenced by the most powerful social subjection. In its more extreme forms, even though we might be forced by the press of the social into taking involuntary actions, this cannot control our beliefs or understanding about such actions. Foucault (1986), for instance, claims no amount of surveillance can control human desire. Therefore, socialisation efforts such as attempts at securing the faithful transfer of knowledge from the social to the individual, as in inter-subjectivity, are unlikely to be completely successful. For instance, the sociologists of knowledge Berger and Luckman (1966) suggest that there are variations in how individuals conceive the social universe, even for those willingly engaging with the suggestion of the social, as with appropriation. On the one hand, the social world is not able to project its suggestion comprehensively or unambiguously, and, on the other, that individuals' engagement with the social will be distinct and characterised by difference. This difference, as noted, is a product of personal histories and individuals' attendant agency and the complex of factors that mediate their cognitive experience: that is, how they make sense of and engage with social world.

Engagement in and learning from vocational practices, therefore, cannot be a process of mere reproduction of what is intended by social forms and encounters. Instead, throughout working life, vocational practices may be elaborated, refined and remade by individuals as their agency and intentionality engages with socially-determined tasks and activities. Hence, the extent by which the suggestion of the social world is able to be exercised is relational. It is dependent upon its capacity to exercise its suggestion and the degree by which individuals take up that suggestion. This also suggests that cultural practices, such as occupations, are remade and transformed through a complex of ongoing interplays between each generation of individuals and the social world as meanings are made sense of, constructed, re-constituted and remade (Bhaskar, 1998; Gergen, 1994). It seems the associations between this remaking and individuals’ on-going 
learning are irreducible. So, the personal contributions to the interdependence between the individual and the social should be included in accounts that aim to explain the ongoing process of learning through work and the evolution of occupational practices that reflect cultural imperatives and local factors that comprise the immediate experience.

\section{Personal agency, and learning and remaking work}

As discussed above, but often de-emphasised in many popular contemporary theoretical accounts, the contribution of personal agency in enacting, remaking and transforming culturally-derived practices is central to the regeneration and transformation of work and its learning. Such a proposition finds support within accounts that emphasise the social. For instance, Baldwin (1930) proposed that human development occurs through "conscious and social accommodations, imitation, invention and volition ...” (p. 4). More than being passive, this imitation is exercised in particular and intentional ways reflecting the interplay between social experience (i.e., the source of imitation) and individuals' construction of what is to be imitated. Earlier, Baldwin (1894) concluded that from early interactions with their parents and others, children develop a "social sense" and learn that these experiences can be unstable or unpredictable. He claimed that children learn from an early age of the uncertainty and unpredictability of their dealings with the social world. One day a request for a biscuit is acceded to, the next rejected. This led to what he referred to as the projective stage in the growth of personal consciousness. In this stage, individuals actively deploy and extend their sense of knowing to monitor and comprehend the potential unpredictability of what they experience in social encounters. Baldwin (1894) proposed this development as being "indescribably subtle and indescribably inter mixed in the subjective ensemble of the growing child” (p. 275). It was through these earlier or pre-mediate experiences that "sense of personal actuation - 'projective agency'" is formed. This process is analogous to that described as microgenetic development (Rogoff, 1990; Scribner, 1985), exercised through what contemporary accounts propose as individuals' epistemological beliefs and agency (Smith, 2006) and intentionality that directs the focus and effort of their conscious thinking and acting. Indeed, from observations of his own children, Baldwin (1898) noted that children come to exercise their private judgement, fight their own battles, and exercise both independence and the vice of obstinacy. That is, he claims that individuals learn through selective engagement and negotiation with their social environment (i.e., in ways that are personally relational). 
Vygotsky also proposed a key role for the agency of the learner. He claimed that while engaged in culturally-derived acts of play, children contributed to their development in ways shaped by their interest and intentionality. He noted that when engaged in play, children extended their capacities in developmental ways, mediated by their own capacities. Moreover, it was the children's actions and agency, rather than their parents', that extended the scope of their development through their actions. That is, their agency extended prospects for the learning (cited in Valsiner \& van der Veer, 2000). Here, Vygotsky appears to contradict contemporary accounts of the Zone of Proximal Development through proposing that the potential and scope for children's development is premised more on learners' personal agency than on their more experienced social partners. The children's agency determined the extent of their development.

Similarly, Cole (2002), a key advocate of cultural historical activity theory, concedes that personal agency is required to both enact and transform these practices. He noted that historically-derived classroom management practices were not helpful for his teacher education students' work in tough and turbulent American high schools. He claimed to be unable to advise his student teachers on how to proceed with their classroom practice. Instead, he stated his students would need to deploy their personal agency in remaking classroom management practices in the classrooms in which they teach. So, it is the agency of individuals in adapting (i.e., remaking) and transforming historically-derived knowledge that is required to sustain and advance the sociocultural practice of teaching in the face of demanding practice.

A related form of selectivity was identified by Goodnow (1990). She notes that individuals decide what problems are worth solving, thereby selecting which socially-derived tasks to engage in and how they should be engaged with, with consequences for their learning. She positions individuals as being actively engaged in their own development and the remaking of cultural practices. In extending views about the agency and selective engagement of the individual with the social world, Valsiner (1998) proposes most human development occurs through individuals actively ignoring and neutralising the social suggestions they are subjected to in everyday life. This, he holds, is essential to buffer individuals' personalities against the constant demands of social suggestion. He notes how efforts of socialising agents (e.g., institutions or parents) are of necessity countered by those who are subject to them, as they are able to ignore or neutralise most of these suggestions, except for the most compelling. Consequently, personal agency is not posterior or reducible to social agency. Instead, although 
not being able "to wish it away", the individual can act independently of that suggestion. Taking Baldwin's $(1898,1930)$ view, individuals' engagement and negotiation with social suggestion (i.e., rebuttal or appropriation), necessitates acknowledging the importance of antecedentsindividuals’ pre-mediate experiences. Gergen (1994), for instance, proposes that, as we move through life, we are continuously confronted by experiences offering new contexts and new challenges.

Yet our actions in each passing moment will necessarily represent some simulacrum of the past; we borrow, we formulate, and patch together various pieces of preceding relationships in order to achieve local coordination of the moment. Meaning at the moment is always a rough reconstitution of the past, a ripping of words from familiar contexts and their precarious insertion into the emerging realisation of the present. (Gergen, 1994, pp. 269-270)

Further, while these personal constructions reflect the past, the agency and intentionality of individuals can also be directed towards the future. Two recent studies investigating workplace participatory practices over time (Billett, Ehrich, \& Hernon-Tinning, 2003; Billett, Smith, \& Barker, 2005) found that much of workers' negotiation and enactment in their working lives could best be characterised as the exercise of individuals' intentionality towards them "being themselves” as enacted through their agency. A sense of self was strongly articulated by these workers in most instances as providing agentic bases to be themselves through their work. Therefore, having discussed the conceptual premises of the relational interdependence between the personal and the immediate social suggestion, it is necessary to identify instances of these phenomena in learning through work. Consequently, the section that follows draws on studies of participating in and learning through work to illustrate and elaborate instances of this relational independence at work.

\section{Instances of relational interdependence at work}

The conceptualisation of learning through work advanced above arose from findings within practical inquiries, albeit informed by deliberations within learning theory. From early investigations into learning within a range of workplace settings, it was concluded that regardless of whether this learning was derived from everyday work activities or intentional workplace 
learning events, a duality existed between the person and workplace settings. This duality, entitled co-participation at work (Billett, 2001a), comprises the affordance (i.e., invitational qualities) of the workplace and how workers engaged with what was afforded them. However, subsequent studies provided evidence that the relationships between individuals and workplaces were not reciprocal or even necessarily collaborative. Hence, the concept of co-participation lacked explanatory power. Instead, the dualities between the social and the personal were found to be more relational: dependent upon negotiations between the personal and the social. These negotiations were shaped by the kinds and degree of workplace affordances and individuals' bases for conceptualising and constructing what was afforded. It is these kinds of relations that are illustrated here.

Hairdressing salons are socially-constructed spaces that are ordered to fulfil the requirements of the culturally-derived and necessary human service of hairdressing. However, the spaces themselves appear to be quite distinct in terms of their organisation and enactment of this form of paid work (Billett, 2001b). For instance, some salons have distinct goals or clientele that shape their practice. In one salon, stylish and transformational haircuts were the core business supported by a particular emphasis on cut and colour. The youngish and inner city clientele frequented this salon because of its reputation for offering the kinds of cuts and styles they wanted. Typically, in this salon the hairdressers have their own clientele and the salon's work is organised around each hairdresser working on their own clients through the entire hairdressing activity. However, another salon had a quite different focus for its business and mode of ordering the work of hairdressing. Here, the work was divided and distributed on the basis of level of hairdressing experience. So, less experienced hairdressers would only perform less critical tasks, whereas more experienced hairdressers completed more complex and critical tasks. Consequently, clients in this salon would have their hair dressed by a number of hairdressers, who might even take over during a phase within the haircut. The goals for this salon were associated with providing good quality and value-for-money haircuts, which would maintain the flow of clients in the small provincial town in which it was located. These two salons, like the others investigated, had particular goals and practices that were shaped by situational factors including the preferences of the owners and/or managers. So, each had a particular culture of practice (Brown, Collins, \& Duguid, 1989) that was a product of the specific goals and preferred approaches that were instances of the cultural practice of hairdressing. 
Much of hairdressers' work is conducted in the public space of these salons, making it easy for the hairdressers to be observed and monitored. Indeed, a practice in which hairdressers engage is to observe clients coming to the salon and the styles they leave with. In many ways, these workplace settings might seem like those where worker discretion outside of the culture of practice (i.e., "what we do here is") might be difficult to exercise. However, there is evidence that the hairdressers were able to exercise personal preferences not only in dressing their clients' hair, but also in the ways that they responded to the demands and press of the workplace. These differences were evident in accounts of their likes and dislikes about their work, how they categorised clients, and how they conceptualised clients' hairdressing needs and provided particular treatments for them (Billett, 2003). The point here is that workers engaged in close physical proximity, where their work could be observed and monitored and in circumstances that might promote inter-subjectivity (i.e., shared understanding). Yet they construed, constructed, and engaged in their hairdressing work in ways that reflected different degrees and kinds of social and personal press. For instance, some of these hairdressers had roles as owners and managers which furnished more privileged positions, but required engagement with other kinds of concerns (managing staff, stock control, ordering, etc.). Others were novices, some of whom were concerned about their standing with both other hairdressers and clients. Yet, in these differing positionings in the social practice there were different responses to "the same” work-related activities.

In all, there was evidence of relational inter-psychological processes and negotiations between the personal and social factors in the accounts of these hairdressers' work that were captured and verified in interviews about their work, and their responses to hairdressing problem scenarios. The legacies of these processes extend beyond the conduct of their work as they constitute learning or changes to their cognitive experience.

Another study focussed on how relatively socially-isolated learners (small business operators) learnt about a new initiative (a goods and service tax) and how to implement it (Billett et al., 2003). It was found that although faced with a similar task that was important to the sustainability of their businesses, there were very distinct ways of engaging with social partners and sources of information among these workers. Here, of necessity, there was a strong exercise of personal agency in determining what this tax meant to the business owner and on what bases they engaged with others and independently to learn about it. As with the hairdressers, the role of 
dispositions (e.g., interests and values) was evident in these workers' engagement and learning about this new taxation system. For some, this new requirement was not a primary consideration for their work, because they were more interested in their occupational practice (i.e., an optician, a veterinarian, an agricultural supplier) than in the details of running a business. Those workers that were highly focussed on profitability, as entrepreneurs or owners of businesses, were often reliant on a steady flow of income or had primary concerns about profitability that might be threatened by this new tax and its administration. Yet, there were those small business operators who, unlike the optician and vet, could not afford accountants and bookkeepers. They had to exercise particular agency in learning about the goods and service taxes and to administer them, in order to remove the financial burden of employing accountants and bookkeepers.

The point here is that there were quite qualitatively distinct responses to the same social suggestion. These responses were more than quantitative (i.e., by degree): they represent diverse and distinct construals and constructions, and, hence, learning. Essentially, the interpsychological processes (i.e., between the personal and the social) were quite distinct for these small business operators. The bases by which the social suggestion (i.e., the need to accommodate the goods and service tax) was able to be exercised and the ways in which these workers construed, constructed and enacted that suggestion were relational. Yet there was interdependence in small business operators' learning. They needed to engage with social partners and sources for this initiative to be successfully implemented. So, both social and personal practices were advanced through this relational interdependence.

Although the examples above represent instances of work that are largely conducted through independent practice, similar relational engagement and learning (i.e., interdependencies) were identified in larger workplaces where work tasks are shared and where performance is premised on working collaboratively. For instance, in teams of information technology specialists and fire fighters, similar inter-psychological processes were evident (Billett et al., 2005).

In this information technology (IT) workspace, there was a standard operating environment within which all the workplace's computers were required to operate and be maintained, a measurable performance feedback and rating system and, given the immediacy of the knowledge required for work, a requirement for workers to collaborate. As threats to the system (e.g., viruses and software problems) tended to arise quickly and threatened the viability of the environment, approaches to solutions for these threats and problems had to be addressed 
quickly, and perhaps uniformly applied and then shared across the workspace. Moreover, in this workplace, where the workers were co-located there was the prospect for sharing of knowledge. Beyond the close engagement and physical proximity of the workplace, there was also a strong suggestion for these workers to engage in social events organised by team members. However, the degree by which these workers elected to engage in these social activities was evidence of personally distinct ways of participating in work more generally.

Of the three IT workers who participated in the study, two of them reported quite distinct work life goals that were inconsistent with those of the work area. One was a very experienced electronics engineer who wanted to use his skills more widely than was possible within the constraints of "work template" of this work area. He also had a preference for work measures based on qualitative accounts of this work in terms of client satisfaction and attempting to resolve a problem for the longer term rather than an immediate solution. Another member of this team was fairly new to IT work after having to retire from his former occupation through injury and retrain as an IT worker. However, his ambitions for this new occupation were not going to be fulfilled through his existing work activities, and so he was planning and making contacts for a move to a different kind of IT work, albeit in the same workplace. He also avoided any engagement in the workplace's social activities conducted outside of work hours. The third participant did much to keep the workplace interactions going and initiated some of the social events. His work history and expertise were consistent with the work of the help desk centre. So the subjectivities of these workers were quite distinct and this shaped in distinct ways how they participated and learnt through their working lives.

Similar findings were identified in the engagement and learning of three fire fighters. These workers engaged intimately and over time with other members of the fire-fighting team. When on shift, they worked, lived, slept and ate together in a common space in circumstances that are likely to promote high levels of inter-subjectivity. Indeed, all three of the participants shared a strong sense of identity as being fire fighters and maintaining and extending that identity was a key motivating contribution to their participation in and learning through work. Also, the workplace had sets of strict norms and practices that needed to be adhered to for work organisation and safety requirements. There were a range of mechanisms which reinforced this "command and control culture", which included particular seating arrangements in the "fire engine” and a battery of permissions and regulations to which the officers were required to 
adhere. One of these was mandatory induction training and examinations for promotions. One informant was an experienced fire fighter from the United Kingdom who, despite his experience, had to complete the probationary processes and be treated as a novice until this process was completed. This also included being assigned the junior seat in the fire engine, as a very exquisite statement about his standing. Another of the participants was given time off to address a family issue and used some of this time to prepare for his examinations that would prepare him to be a senior officer. He had a set of specialist skills that already permitted him some autonomy and authority when fighting fires. Another was a senior officer who was seeking to continue his career in the service, whilst maintaining his identity as an active and expert fire fighter. Therefore, while there was a common form of work that these workers strongly identified with, their positions within the service meant there bases for engagement in and learning more about fire fighting were quite distinct. Here, even the issues associated with identity maintenance were so distinct as to suggest quite different inter-psychological processes.

These findings reinforced the salience of these individuals’ subjectivities, identities, and processes associated with learning throughout working life. So, for these workers, the conception of self needed to be inclusive of propositions about achieving goals of personal autonomy, and goals of increasing competence subjugations of the social suggestion to advance their plans for achieving these goals. Engagements and learning are identifiable that shape how workers elected to engage in and attempted to transform their work practices and their working lives over time. These workers' earlier experiences provided the premises for their intentionality, including how they interpreted and engaged with subsequent experiences: their knowing, ways of knowing, subjectivities, gaze and their epistemological beliefs. Their agency was directed by a quest to "be themselves” in changing workplace circumstances.

Learning throughout working life, in this way, can be viewed as a negotiated but transformative journey as individuals selectively negotiate their engagement in work, and changing work requirements, work practices and the shifting bases for participation in work. This includes reshaping their sense of self through the agentic ongoing and transformative practices of seeking the ontological security of being themselves. So, individual workers are not hostage to cultural norms or situated social contributions. Certainly, to greater or lesser degree they are pressed to engage actively with the suggestions of the social world they encounter in their everyday work. Yet they were able to modify, remake or even rebuff these suggestions, by 
degree. It is these interplays that make up individuals' learning as they construe what they experience and construct a response that has legacies for both the individual (i.e., learning) and the workplace (i.e., remaking of practices).

More than just making contributions, in terms of their own knowledge, capacities and so on, individuals selectively shape their immediate social encounters and subsequent outcomes through personal volition and need for purposeful action. Hence, it follows that individuals need to be conceptualised as being personally agentic, yet socially shaped over time (Mead, 1913), albeit in potentially unique ways that arise from particular personal histories. Consequently, within this view, conceptions of subject and subjectivities shift from "being placed under" to those in which individuals are viewed in terms of self and engaging in struggles for personal coherence and ontological security (Giddens, 1991), in ways analogous to the Piagetian (1968) quest for equilibrium.

\section{Relations in interdependence at work}

The contribution here is to propose that the inter-psychological process of learning through work comprises an interdependence between the immediate social experience and individuals' appropriation of that experience. It constitutes a dualistic and relational base for individuals' learning and remaking of their work activities. Therefore, to understand learning through work, it is necessary to account for the relational bases of this learning. However, we need to be reminded, in drawing on Baldwin $(1894,1898)$, that a consideration of relational bases between the individual and the social is far from a new consideration within socially-oriented psychological perspectives of learning. Also, from a sociological perspective, Giddens (1991) opposes a polarisation of agency and structure, viewing structures as enabling as well as constraining. Valsiner (1994) and Bhaskar (1998), although acknowledging the ubiquity of social influence, also emphasise the relatedness between individuals' interests and goals, and those comprising the social suggestion. Of salience here is that this relatedness stands at the centre of the inter-psychological processes through which individuals' learning and their remaking of practice arise. Consistent with this, Newman, Griffin and Cole (1989) claim that Vygotsky's greatest contribution was not in linking the external and internal, but in emphasising the dialectic between the inter- and intra-psychological. Here, it has been proposed that the social suggestion is exercised with different levels of potency and individuals exercise different levels of 
responsiveness to social suggestion and by different degrees of engagement. For Valsiner (1994), this relatedness ranges from total involvement to being wholly disengaged. For instance, individuals may not even be aware of the social press, subjugation or discourse or other social forms in ways that influence the responses of others.

Importantly, in existing accounts where the relations in inter-psychological processes are discussed, they are positioned as being reciprocal (Lawrence \& Valsiner, 1993; Rogoff, 1995), mutual, co-constructed (Valsiner, 1994), and co-participative (Billett, 2002). Indeed, a key claim from sociocultural theory is that as partners come together, the idiosyncratic nature of their knowledge moves to be shared with partners (Newman, Griffin \& Cole, 1989). Hence, intersubjectivity is seen as an important outcome of social interactions, particularly of the proximal kind. However, rather than being equal in their contributions, the interdependence between the social suggestion and individual agent is more likely to be relational in unequal, inconsistent and disjointed ways. This is because both individuals' scope for acting agentically, conceptualising what they experience in person-dependent ways, and the potency of social suggestion will differ depending upon circumstances, activities or interactions. Therefore, the intents, processes and outcomes of these interdependencies are so inherently subject to difference that claims about mutuality seem highly ambitious. Comprehensive inter-subjectivity (i.e., shared understanding between situationally accessible knowledge and interlocutor), as in socialisation, stands as an ideal intra-psychological outcome that is unlikely to be realised. The relational nature of this interplay suggests that equal personal or social contributions in inter-psychological processes and shared intra-psychological attributes and/or outcomes as inter-subjectivity are rendered increasingly unlikely.

Furthermore, the difficulty of securing inter-subjectivity renders as necessary individuals' need to actively engage in and remake the cultural practices they are engaged in, if for no other reason than their need to enact them with effect. Because it is difficult or impossible to provide unequivocal guidance about how a work task needs to be conceptualised and then enacted, individuals inevitably have to engage agentically in remaking the culturally-derived practices that constitute their work. So when faced with a work task, whether familiar or new, individuals undertake the activity by drawing variously upon their capacities and attempting to make sense of the task before them, as Gergen (1994) proposes. Within cognitive theory, this process is referred to as enacting approximations of tasks of be achieved (Anderson, 1982). The process of learning 
these tasks is held to be one of securing increasingly mature approximation of the targeted performance. However, even when externally observable performance might be seen to be the same or similar, there can be no confidence that the learning will lead to shared meaning (i.e., inter-subjectivity). Instead, there is likely to be a quite idiosyncratic structuring of the knowledge that renders apparently similar performances (Billett, 2003). Therefore, learning throughout working life needs to be seen as a relational concept, with the relationship being mediated by the personal agency and intentionality of the individual. This learning occurs as workers enact their subjectivity in attempts to secure and realise ontological security in changing work requirements. Such a view questions easy assumptions about inter-subjectivity that are often central to considerations of instruction as individuals learn with some fidelity what they are being taught.

In all, a consideration of relational interdependence attempts to open up and overcome dualisms in understanding subjectivities and self from definitions that are overly centred on either individuals, their feelings and behaviours, or those relating to social structures. Instead, a duality comprising contributions from both, but importantly the relations between them, has been advanced.

\section{References}

Anderson, J. R. (1982). Acquisition of cognitive skill. Psychological Review, 89(4), 369-406.

Archer, M. S. (2000). Being human: The problem of agency. Cambridge: Cambridge University Press.

Baldwin, J. M. (1894). Personality-suggestion. Psychological Review, 1, 274-279.

Baldwin, J. M. (1898). On selective thinking. The Psychological Review, V(1), 1-24.

Baldwin, J. M. (1930). James Mark Baldwin. In C. Murchison (Ed.), A history of psychology in autobiography (pp. 1-30). Worcester MA: Clark University.

Berger, P. L., \& Luckman, T. (1966). The social construction of reality. Harmondsworth, Middlesex: Penguin.

Bhaskar, R. (1998). The possibility of naturalism. London: Routledge.

Billett, S. (2001a). Coparticipation at work: Affordance and engagement. In T. Fenwick (Ed.), Sociocultural perspectives on learning through work (pp.63-72). San Francisco: Jossey Bass/Wiley.

Billett, S. (2001b). Learning in the workplace: Strategies for effective practice. Allen and Unwin, Sydney.

Billett, S. (2002). Workplace pedagogic practices: Co-participation and learning. British Journal of Educational Studies, 50(4). 457-481.

Billett, S. (2003). Sociogeneses, activity and ontogeny. Culture and Psychology, 9(2), 133-169.

Billett, S. (2006a) Relational interdependence between social and individual agency in work and working life. Mind, Culture and Activity, 13(1), 53-69. 
Billett, S. (2006b). Work, subjectivity and learning. In S. Billett, T. Fenwick, \& M. Somerville (Eds.), Work, subjectivity and learning: Understanding learning through working life (pp. 1-20). Dordrecht, The Netherlands: Springer Academic Publication.

Billett, S., Ehrich, L., \& Hernon-Tinning, B. (2003). Small business pedagogic practices. Journal of Vocational Education and Training, 55(2), 149-167,

Billett, S., Smith, R., \& Barker, M. (2005). Understanding work, learning and the remaking of cultural practices. Studies in Continuing Education, 27(3), 219-237.

Billett, S., \& Somerville, M. (2004). Transformations at work: Identity and learning. Studies in Continuing Education, 26(2), 309-326.

Brown, J. S., Collins, A., \& Duguid, P. (1989). Situated cognition and the culture of learning. Educational Researcher, 18(1), 32-34.

Cole, M. (1998). Can cultural psychology help us think about diversity? Mind, Culture and Activity, 5(4), 291-304.

Cole, M. (2002, April). Building centers of strength in cultural historical research. Paper presented at the Annual Meeting of the American Education Research Association, New Orleans.

Engestrom, Y. (1993). Development studies of work as a testbench of activity theory: The case of primary care medical practice. In S. Chaiklin \& J. Lave (Eds.), Understanding practice: Perspectives on activity and context (pp. 64-103). Cambridge, U.K: Cambridge University Press.

Foucault, M. (1986). The care of the self: The history of sexuality, vol. 3 (R. Hurley, Trans.). Harmondsworth: Penguin.

Gergen, K. J. (1994). Realities and relationships: Soundings in social construction. Cambridge, Mass.: Harvard University Press.

Giddens, A. (1984). The constitution of society. Cambridge: Polity Press.

Giddens, A. (1991). Modernity and self-identity: Self and society in the late modern age. Stanford: Stanford University Press.

Goodnow, J. J. (1990). The socialisation of cognition: What's involved? In J. W. Stigler, R. A. Shweder \& G. Herdt (Eds.), Cultural psychology (pp. 259-286). Cambridge: Cambridge University Press.

Grey, C. (1994). Career as a project of the self and labour process discipline. Sociology, 28(2), 479-497.

Lave, J. (1990). The culture of acquisition and the practice of understanding. In J. W. Stigler, R. A. Shweder \& G. Herdt (Eds.), Cultural psychology (pp. 259-286). Cambridge: Cambridge University Press.

Lave, J., \& Wenger, E. (1991). Situated learning - Legitimate peripheral participation. Cambridge: Cambridge University Press.

Lawrence, J. A., \& Valsiner, J. (1993). Conceptual roots of internalisation: From transmission to transformation. Human Development, 36, 150-167.

Luria, A. R. (1976). Cognitive development: Its cultural and social foundations. Cambridge: Harvard University Press.

McLaren, M. A. (1997). Foucault and the subject of feminism. Social Theory and Practice, 32(1), 109-128.

Mead, G. H. (1913). The social self. Journal of Philosophy, Psychology, and Scientific Method, 10, 374-380.

Newman, D., Griffin, P., \& Cole, M. (1989). The construction zone: Working for cognitive change in schools. Cambridge: Cambridge University Press. 
Ratner, C. (2000). Agency and culture. Journal for the Theory of Social Behaviour, 30, 413-434. Rogoff, B. (1990). Apprenticeship in thinking - Cognitive development in social context. New York: Oxford University Press.

Rogoff, B. (1995). Observing sociocultural activity on three planes: Participatory appropriation, guided participation, apprenticeship. In J. V. Wertsch, A. Alvarez, \& P. del Rio (Eds.), Sociocultural studies of mind (pp. 139-164). Cambridge: Cambridge University Press.

Salomon, G. (1997). No distribution without individuals' cognition: A dynamic interactional view. In G. Salomon (Ed.), Distributed cognitions: Psychological and educational considerations (pp. 11-139). Cambridge: Cambridge University Press.

Scribner, S. (1985). Vygostky's use of history. In J. V. Wertsch (Ed.), Culture, communication and cognition: Vygotskian perspectives (pp. 119-145). Cambridge: Cambridge University Press.

Searle, J. R. (1995). The construction of social reality. London: Penguin.

Smith, R. (2006). Epistemological agency: A necessary action-in-context perspective on new employee learning. Studies in Continuing Education, 28(3), 291-304.

Taylor, C. (1985). Human agency and language: Philosophical papers 1. Cambridge: Cambridge University Press.

Valsiner, J. (1994). Bi-directional cultural transmission and constructive sociogenesis. In W. de Graaf \& R. Maier (Eds.), Sociogenesis re-examined (pp. 101-134). New York: Springer.

Valsiner, J. (1998). The guided mind: A sociogenetic approach to personality. Cambridge: Harvard University Press.

Valsiner, J. (2000). Culture and human development. London: Sage Publications.

Valsiner, J., \& van der Veer, R. (2000). The social mind: The construction of an idea. Cambridge, UK: Cambridge University Press.

Wenger, E. (1998). Communities of practice: Learning, meaning, and identity. Cambridge: Cambridge University Press.

Wertsch, J. V. (1998). Mind as action. New York: Oxford University Press. 